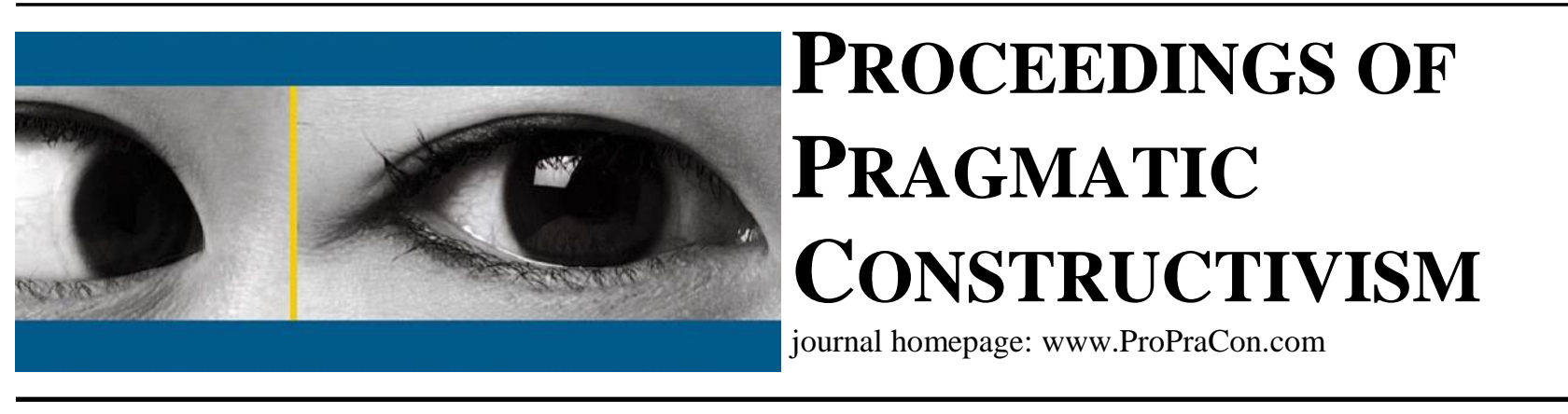

\title{
The validity in performance measures used in hospital planning
}

\author{
Antonio Leotta \\ Associate Professor in Accounting, Department of Economics and Business, \\ University of Catania (Italy), corso Italia, 55, Catania, Italy; antonio.leotta@ unict.it \\ (corresponding author) \\ Daniela Ruggeri \\ Research Fellow in Accounting, Department of Economics and Business, \\ University of Catania (Italy), corso Italia, 55, Catania, Italy; d.ruggeri@unict.it
}

Monica Castro

Administrative Manager, Azienda Ospedaliera Universitaria, Policlinico - Vittorio Emanuele Catania (Italy) monica.castro@policlinico.unict.it

\begin{abstract}
The present research aims to discuss the theoretical conditions for validity in performance measures used in hospital planning. In doing so, the research draws on a new emerging research paradigm, called Pragmatic Constructivism (Nørreklit et al., 2010). It conceives of accounting as a social reality constructed through the integration of four ontological dimensions: facts, possibilities, values and communication. The conditions for validity in performance measures used in hospital planning are examined drawing on Nørreklit et al. (2007). Specifically we investigate theoretical conditions for validity in accounting performance measurement, analysing the ontological and epistemological nature of accounting data. The theoretical framework is applied to interpret the empirical evidence coming from a case of an Italian hospital located in the south of Italy. The empirical results showed how the theoretical framework helps to better understand the validity in some of the performance measures contained in the hospital plans: the validity of knowledge of past results is examined by verifying the correspondence of performance measures with the past activity of the hospital; while the validity of the estimations of future results is analysed by verifying their coherence and consistency.
\end{abstract}

\section{Introduction}

The introduction and diffusion of New Public Management philosophy has been a way to deal with the problem of recovery efficiency and effectiveness in public organisations. A call for reliable information comes from the need to solve these problems, estimating the future outputs and outcomes. Also, performance measurements have to be valid in order to be communicated to the relevant stakeholders. Among the public sectors that are experiencing these concerns, the healthcare is one of the most relevant. The peculiarity of the healthcare activity and its centrality make needs for efficient and effective healthcare management more pronounced. Moreover, the relevance and legitimacy acknowledged to specific stakeholders, such as patients, citizens, governments, reflect on an increase in the need for transparency. Accounting, as a discipline, is required to provide instruments and techniques that are valid in producing reliable information. The latter consists of performance measures and estimations of the outputs and outcomes expected from the 
strategy deliberated in the healthcare organisations (Aidemark and Funck, 2009; Abernethy, 2007; Johanson et al., 2006; Paranjape et al., 2006; Urrutia and Eriksen, 2005; Moullin, 2004; Curtright et al., 2000). The Performance Plan (PP) is a managerial instrument directed to address the abovementioned concerns. What makes the performance measures contained in PP valid instruments for the disclosure of information on future outputs and outcomes is the most important question related to the above discussion. Since the mainstream accounting literature, moving from the realistic paradigm, has left this question open (Nørreklit et al., 2014), alternative paradigmatic assumptions need to be considered.

The present research aims to discuss the theoretical conditions for validity in performance measures used in hospital planning. In doing so, the study draws on a new emerging research paradigm, called Pragmatic Constructivism (Nørreklit et al., 2006; 2010). It conceives of accounting as a social reality constructed through the integration of four ontological dimensions: facts, possibilities, values and communication. Particularly, facts are necessary as a basis of action but they also are related to the possibilities which are grounded in the facts. Furthermore, possibilities create room for choice, but they only function if there is a reason (value) to choose and prefer one possibility to the other. Finally, the integration of facts, possibilities and values must be expressed in communication in order to enable action in a social setting. In the present research, conditions for validity in performance measures used in hospital planning are examined drawing on Nørreklit et al. (2007). The latter investigated theoretical conditions for validity in accounting performance measurement, analysing the ontological and epistemological nature of accounting data. Drawing on their analysis, we see PP as constructed by means of data that, ontologically, are of subjective and objective nature. Epistemologically, data constructing PP are based on both measurement results, providing knowledge, and on estimations and targets, providing beliefs. Being planning an accounting technique based on providing measurements of objectives and targets related to future outputs and outcomes, the validity of the performance measures contained in a PP depends on how objectives and targets are developed integrating both measures of past results, which constitute knowledge, and estimations of future outputs and outcomes, which constitute beliefs.

The theoretical framework outlined in the first part of the paper is applied to interpret the empirical evidence coming from a case of an Italian teaching hospital located in the south of Italy. Data are mainly gathered retrospectively from managers' interviews and from two subsequent PP, covering the period from 2013 up to 2017.

The case discussion shows how the theoretical framework we discussed is able to offer guidelines for analysing the validity in performance measures used in hospital planning. It suggests examining the validity of knowledge of past results by verifying the correspondence of performance measures with the past activity of the hospital. Also, it suggests examining the validity of the estimations of future results by verifying their coherence and consistency. Thus, the relevant results come both from the specifics of the context and from the extent to which the theoretical framework is useful for dealing with a real case. As main results, the case evidence shows: first the impact of the performance planning process, whether its objectives was imposed or negotiated, on the validity of the measures contained in it, second the interdependence between the institutional and the organisational coherence, as two dimensions of coherence that cannot be analysed separately.

The following sections outline the theoretical framework (section 2), describe the research methodology (section 3) and present the case evidence interpreting it from the theoretical lens described previously. Results are discussed and future lines for research are proposed in a concluding section.

\section{In search for valid performance measures}

\subsection{Accounting as a means for searching for the truth: the view of pragmatic constructivism}

How accounting practice can represent the truth is a question posed by accounting scholars moving from different philosophical positions. How this question has been addressed depends on the concept of truth assumed. Conceiving of truth as a correspondence between a measure and the facts that it represents entails that measure is considered a valid measure if its representation is a faithful reflection of the facts observed. Thus, for example, the manufacturing cost of a product is a valid measure if it reflects the value of the resources consumed for manufacturing that product. Such a conception of truth, however, is incomplete as it does not take into account the logical operations that are necessary to represent the manufacturing of a product through a cost configuration. The presence of assets whose costs are joint with respect to the different time periods and product lines requires a choice of some logical criterion to allocate those costs. The resulting amount of cost allocation and depreciation are conjunctures whose validity cannot be judged in terms of correspondence with respect to an external fact, as no external fact can be traced. Logical coherence and consistency are further criteria to be considered in the search for truth. Thus, in assessing the validity of any performance measure both factual and logical dimensions of truth have to be considered. These two dimensions, however, have to be integrated with the values that motivate people to act. A highly innovative firm, for instance, is willing to reduce the life period of its own assets, increasing the amount of annual depreciations. This strategy has to be understood and accepted by all firm's 
stakeholders, otherwise the higher value of depreciation may be perceived as the result of earnings management. Put it other ways, any performance measure should reflect the values shared by its users and is part of a language; it is valid if it supports communication among its users.

Following this reasoning, we focus on the validity of measures conceived as an instrument which mediates between the different perspectives in selecting the relevant facts on which future actions and behaviours are defined. In doing so we stay away from a paradigm that is ontologically rooted in the mechanical realism and combined with a positivist epistemology that considers the measure as an empirical and objective assignment of the real world (Kaplan and Norton 1996; Ittner and Larcker,2003). We apply a framework for reality which defines it as the result of the continuous relation between the actor and the world. Specifically, we study performance measures through a new paradigm that can overcome the limits of the main stream functionalistic paradigm. This new paradigm is called "pragmatic constructivism". It assumes reality as the result of the continuous relation between the actor and the world. Any reality is not a general construction but a construction valid if it takes into account how the actor belongs to its world and how the world is the world of the actor. To do so, reality comes from the integration of four main dimensions: facts, possibilities, values and communication, as in the example discussed above. The authors who proposed this perspective justified the inclusion of all the four dimensions as follows: "Facts are necessary as a basis of action. Facts alone are insufficient. If there are no possibilities there can be no action” (Nørreklit et al., 2010, p. 738).

Possibilities are disclosed by logic and refer to the future. Thus, while facts are something that happened in the past, logic is the way to disclose possibilities for the future. Then, they continue: "The possibilities must be grounded in the facts. Otherwise they are fictional. Further, possibilities create room for choice, but they only function if there is a reason to choose and prefer one possibility to the other i.e. if the actor has values and the values lie within the range of one's possibilities. Finally, the integration of facts, possibilities and value must be expressed in communication in order to enable action in a social setting" (ibidem, p. 738).

How performance measures support communication among people is explained drawing on the rhetorical category of "topos". As specified by Nørreklit et al. (2007): "The subjective topos is the communicative expression of the mode of thinking by which an individual perceives, understands and interprets reality" (Nørreklit et al., 2007, p. 183). Performance measures are based on organisational topoi, as they draw on the social idea and concepts, interpretations and patterns of thought developed within the organisation. Thus, the validity of performance measures refers to the validity of the organisational topoi they are based on.

Performance measures are valid if they provide the truth. But what do we mean by truth? As said before, different concepts of truth can be considered: truth in terms of correspondence between measures and facts; truth in terms of logical coherence and consistency. Considering the four ontological dimensions (facts, logic, values and communication) which construct reality as the result of the relation between the actor and the world, performance measures are valid to the extent that the organisational topoi they are based on help individuals to act within their organisational world, and help the firm to act within its economic and institutional world. A pragmatic notion of truth is thus adopted. The authors explain: "According to a pragmatic theory of truth, a statement is true if it leads to successful actions - i.e. if its future predictions hold true" (Nørreklit et al., 2007, p. 186). However, the limit of this pragmatic notion is that "one can only know the truth after having tried to apply it in action. One cannot know the future before it has become the past" (ibidem, p. 187). The only way to look for the truth in a social setting is to follow a learning approach to validity and truth. Such an approach combines all the aspects of truth related to the four ontological dimensions discussed above.

The authors, thus, propose a learning approach to validity and truth by distinguishing proactive and pragmatic truth: "Proactive truth is truth we achieve when we combine the criteria of correspondence and coherence. Pragmatic truth is the realised result. While proactive truth gives us expectations and anticipations, pragmatic truth tells us whether our expectations were realistic. The proactive truth is based on our knowledge, concepts and calculations. It relies on the information available in our epistemic platform. Pragmatic truth is an expression of our experience as actors and observers in the phenomenal word" (ibidem, pp. 196, 197). And they further explain: "The difference between proactive and pragmatic truth underpins the fact that we learn and continuously improve our knowledge system" (ibidem, p. 187).

\subsection{The pragmatic constructivist view to the design of a performance measurement system}

Drawing on this theoretical base, the authors discuss how designing a valid performance measurement system. They identify the following steps: 
“(1) Understanding the task of a performance measurement system.

(2) Grounding - the performance system as a phenomenon.

(3) Modelling and dimensionalizing the epistemic platform, bearing in mind:

(a) internal coherence;

(b) external coherence: company and institutional coherence; and

(c) the epistemic platform: truth versus beliefs.

(4) Proactive truth, real truth and pragmatic learning" (ibidem, p. 198).

The first two points require understanding how the business is pragmatically coherent through integrating facts, values, possibilities and communication, and thus drawing the conditions for the firm to realise successful performance.

Modelling and dimensionalising the epistemic platform requires an analysis of the different kinds of coherence to be pursued, which are aspects of the pragmatic coherence. The design of a performance measurement system requires the development of "a theory that reflects the performance system in such a way that it can be used to observe and improve its coherence" (ibidem, p. 200).

Internal coherence within the performance system is pursued by defining concepts about performance dimensions, namely customer satisfaction, cost efficiency, service quality and the like. The definition of concepts can be both vertical and horizontal. Vertically, concepts are defined in relation to the variables used in the measurement process, at the operational level. Different levels of abstraction can be noted: the lowest level refers to the phenomenological ground; the highest level refers to the theoretical one. Thus, vertically, concepts are defined following a grounding theory approach, where a criterion of truth as correspondence is followed. Furthermore, concepts are defined horizontally in relation to other concepts. This is the case of performance concepts that are not easily translated into measures. Think about such concepts as goodwill and social capital. For the model to be operational, specific relations between concepts have to be established. These relations must be internally coherent. If not, the model does not generate information on what is true or false. Moreover, the theoretical coherence of the model relates to operational coherence.

External coherence is distinguished into company coherence and institutional coherence. Company coherence means that the conceptual framework of performance measurements derives from the integration of the factual possibilities, values and language of the organisational actors. Institutional coherence, instead, can be verified through "the logical possibility for the firm to function in the institutional and competitive environment" (ibidem, p. 205).

Correspondence is established between performance as a phenomenon, and its measures. This requires data that can be related to business phenomena. Figure 1 offers an overview of the ontological and epistemological nature of the data of different financial and management accounting phenomena.

Figure 1 - The ontological and epistemological nature of accounting data

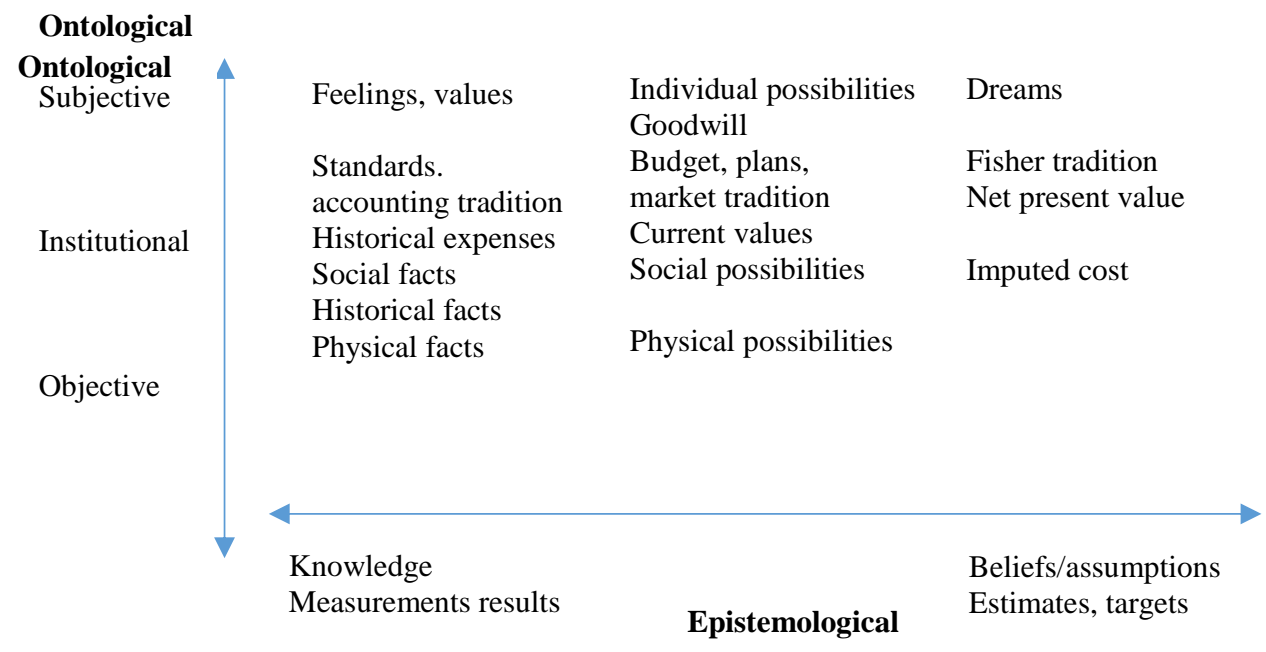

source: our redrawn by Nørreklit et al., 2007, p. 209 
The extent to which accounting data are expression of knowledge depends on how they integrate facts, logic, values by means of proper rules of accounting used as a language.

\subsection{In search for valid performance measures to be used in hospital planning}

For the purpose of the present paper, we discuss the theoretical conditions for validity in performance measures to be used in hospital planning. The role played by the healthcare activity in the social environment and its centrality have made needs for efficient and effective healthcare management. These needs have been emphasised by NPM reforms which have fostered the introduction into healthcare organisations of performance planning.

Thus, over recent decades, many healthcare organisations have modernised their management accounting systems by designing performance plans and the related performance measurement system (PMS) (Aidemark and Funck, 2009; Abernethy, 2007; Johanson et al., 2006; Paranjape et al., 2006; Urrutia and Eriksen, 2005; Moullin, 2004; Curtright et al., 2000). Some contributions have underlined problems connected to the implementation of the PMS in healthcare context in estimating the future outputs and outcomes. The criticism refers to both the theoretical model and to the practical application of the PMS used (Nørreklit, 2003). The healthcare literature on the BSC in the health sector reveals that healthcare stakeholder acceptance is an essential element in its successful implementation (Aidemark and Funck, 2009; Northcott and France, 2005; Radnor and Lovell, 2003; Zelman et al., 2003; Inamdar and Kaplan, 2002; Voelker et al., 2001; Kaplan and Norton, 2001).

Moreover, one of the main concerns in the management literature on healthcare organisations has been the copresence of two main logics underpinning organisational behaviour, i.e. managerial and professional logics, often seen as causing resistance and difficulties in new control system implementation (Chua and Degeling, 1993; Covaleski, Dirsmith, and Michelman, 1993; Doolin, 1999; Jacobs, Marcon, and Witt, 2004; Lehtonen, 2007; Lowe and Doolin, 1999; Weiner, Maxwell, Sapolsky, Dunn and Hsiao, 1987). Power struggles between managers and clinicians have been considered as one of the main arguments in explaining why attempts to implement new management accounting control systems have failed to meet expectations (Abernethy \& Stoelwinder, 1995; Chua \& Degeling, 1993; Covaleski et al., 1993; Doolin, 1999; Jones, 1999; Lapsley, 1994; Lehtonen, 2007; Pettersen, 1995, 2001; Weiner et al., 1987). The multiple logics, which characterised an hospital as an hybrid organisation, sometimes can converge when physicians encounter calculative practices of managerial accounting adopting management accounting techniques (what is defined as hybridisation phenomenon by Kurunmaki, 2004) or when accounting information penetrates deeply into the organisation, making healthcare professionals cost-conscious and increasingly aware of their limited financial resources (Lehtonen, 2007). Otherwise, the managerial logic, expression of a bureaucratic control, may conflict with professional control, deriving from standards and values shared by professional networks, so implying a failure of accounting system implementation (Abernethy \& Stoenwinter, 1995).

The two logics can be conceptualised as "topoi" that is specific ways of reasoning in communication and in analysing possibilities and relating these to values which depend on the basis of people life experience and learning. Considering that, hospital organisations, by coordinating and integrating the various subjective topoi, form a coherently functioning unit (Nørreklit et al., 2006).

Given the co-presence of multiple logics, hospital organisation "runs by a set of conceptual topoi where a pragmatic integration of the four dimensions has to be made for each activity in interaction with other activities....The condition for making such concepts is that the dimensions to be integrated are taken into account in the concepts that constitute the topoi, i.e. the factual, the logical-modal driving possibilities, the subjective-social values and language". (Nørreklit et al., 2014, p.32). In this sense, the performance measures contained in the PP have to be valid in order to be communicated to the relevant healthcare stakeholders.

According to the framework proposed by Nørreklit et al. (2007), we focus on plans as accounting phenomena. The authors observe: "For planning and control we have institutional facts, and collective expectations as well as subjective expectations as to institutional phenomena. This distinction implies that some data used by accounting represent knowledge while some are only beliefs and assumptions. Necessarily, estimating future performance measurements will to some extent depend on the intuition of management, because not only past results but also the impact of future opportunities form part of the performance picture" (ibidem, p. 212).

Being planning an accounting technique based on providing measurements of objectives and targets, validity of its content depends on how objectives and targets are developed integrating both measures of past results, which constitute knowledge, and estimations of future outputs and outcomes, which constitute beliefs. In particular, being planning oriented to the future, based on past results, it is a technique for providing beliefs based on knowledge. While beliefs on future events can be constructed by following the logical criteria of coherence and consistency, knowledge on past events 
can be based on the logical criteria of coherence and consistency, and on the factual criterion of correspondence. As the authors explain: "The epistemological platform, in combination with a model reflecting the coherence of the performance system, is the proactive truth - i.e. the operating knowledge with which we conceive our situation in the world" (ibidem, p. 212).

A learning theory of truth thus is drawn as an approach to deal with the difference between proactive and real truth, hence the role of management accounting as a system of learning: "The real truth depends on the outcome of the accounting endeavours and may therefore differ from the proactive truth. Hereby the learning perspective becomes the objective of installing management accounting systems" (ibidem, p. 213). And they specify: "The observation and analysis of the difference or deviation between the expected and the realised is the vehicle of management control and accounting as a system of learning" (ibidem, p. 214).

The validity of the performance measures contained in a PP derives from their aptitude to be used as a system of learning and to integrate the different values of the actors involved in selecting the relevant facts that are perceived as the bases for future actions. In particular, considering the multiple logics around an hospital conflicting logics can persist and be sustained through the mediating role of accounting.

In the above discussion, healthcare organisations have been presented as characterised by the presence of multiple perspectives, namely healthcare professional and administrative perspectives, that are different ways of thinking and can be understood in terms of different topoi. Moreover, healthcare organisations are mostly articulated within an healthcare system, with different hierarchical levels. An hospital is thus an organisation that has to follow different kinds of coherence and this has to be considered for the validity of the performance measures used. Therefore, the present paper aims to better understand which conditions make the use of performance measures in a hospital PP a valid means to provide true information, in the pragmatic sense explained above.

\section{$3 \quad$ Research methodology}

In order to improve our understandings of the validity of the performance measures contained in a PP, we carried out a case-study at a large teaching hospital located in the south of Italy, where we examined two subsequent PP, covering the period from 2013 up to 2017.

We focused on this research period: firstly, because the PP was mandatory in 2010 into Italian hospitals and produced its effects at the end of the first triennium; secondly, because the validity of PP depends on how objectives and targets are developed integrating both past results and estimations of future outputs and outcomes. Thus, in order to analyse the validity in performance measures contained in the hospital plan we refer the planning process to the second triennium.

The specific hospital was chosen for two main reasons: firstly, for being a large teaching hospital, characterised by a high organisational complexity due to the recent merger with another hospital located in the same city, hereafter called: hospital B; secondly, for the relevance of adjustments to performance measures which occurred during the research period.

The case research followed a retrospective approach, intended to grasp subjects' perceptions of the administrative and professional people involved in the performance planning (Jeacle, 2003; Jonsson, 1998; Scapens, 2004; Walsham, 2006). In our construction of these perceptions, we tried to direct the attention of the people in the field to the aspects they perceived as relevant in terms of both causes and consequences of the examined validity of the performance measures. We also formed our own perception of validity of PP drawing on hospital's archival data, considering the PP, the budget negotiation forms, the objective reports for each department and for each operational units and other internal documents being relevant for the validity of PP.

Data were gathered over the period from October 2015 to March 2016. Our retrospective approach limited data sources to archive and field data coming from interviews with the controller, the past controller, the financial accountant, the department managers who were directly involved in the planning process.

More specifically, we collected archive data from internal documents, such as objective and performance reports, the PP related to two trienniums, and from the firm's web site. Field data came from semi-structured interviews conducted during the month of March 2016 with the controller, the past controller, the financial accountant, the department managers, who were selected from the organisational personnel working at the hospital. These interviewees represented the interests of the different actors involved in the planning process. Interviews mostly aimed at gathering individual perceptions of the appropriateness of the performance measures adopted in order to evaluate their coherence and consistency. 
The interviews, which lasted an hour and twenty minutes on average, were not type-recorded because of the confidential nature of the issues discussed (Kajüter and Kulmala, 2005), and were conducted in an informal style. All were written down in a draft-report and shared with the interviewees.

The limit of relying on retrospective approach consists in asking interviewees to describe, explain and reflect on events they had experienced (Nor-Aziah and Scapens, 2007) as respondents misreport their past choices in order to appear more consistent with their current choice (Shachar and Eckstein, 2007). We do not see such a bias as a limit to the validity of this study, because we contain it through data triangulation.

\section{$4 \quad$ In search for valid performance measures used in the planning process. The case of an Italian teaching hospital}

The PP adopted by the Italian hospital under study is a three-year planning document that defines the hospital resource allocation in line with national and regional health planning and budget constraints. It aims to make explicit the objectives, targets and performance measures at each department and operational unit of the hospital.

The PP is developed based on the guidelines provided by the Commission for the Evaluation, Transparency and Integrity of Public Administration (CIVIT is the Italian acronym). The main parts of the PP structure, which reflect the steps of its formulation are: 1) the definition and assignment of the objectives to be achieved, the expected values of results and their performance measures; 2) the definition of the relationships between objectives and resource allocation; 3 ) the monitoring and the implementation of corrective actions; 4) the performance measurement and the evaluation of organisational and individual performance; 5) the description of the incentive system; 6) the form of communication of performance reporting to the organisational actors and the other external stakeholders.

The PP is a result of the NPM philosophy, which informed the Italian public reform directed to recovery efficiency and effectiveness in the public organisations. The introduction and use of managerial tools, such as PP, orient the single organisations to follow the guidelines of the national and regional governments. Thus, in the Italian healthcare system, the regional guidelines coming from the Regional Health Plan and the annual targets assigned by the Region to the general manager of the hospital reflect the limits imposed by national and regional financial provisions. These guidelines represent the starting point for the formulation of PP. The actors involved in this process translate the hospital strategy into strategic objectives, which in turn are declined into the operational objectives assigned to the department managers. Each operational objective is associated with performance measures and targets. This is the PP vertical dimension.

The PP identifies strategic areas, which specify the institutional and the hospital's mission. The definition of these areas stems from a joint analysis of internal and environment factors. The strategic areas identified are: organisational efficiency; appropriateness of production and management; innovation and development. This is the PP horizontal dimension.

Through the annual budgeting process, each operational unit is involved in the achievement of strategic objectives. In doing so, during the negotiation phase, the strategic objectives are translated into specific operational objectives and measured through specific performance measures. The latter are linked to the incentive system that assigns them a proper weight in the evaluation process.

Before starting the negotiation procedure, the controller and the administrative staff who are involved in this process analyse the level of revenues and costs occurred during the previous three years in the departments; then they identify the minimum levels of productivity required for the year and assign the economic budget to each department.

Referring to the budget negotiation, the past controller argued: "The budget negotiation procedure was introduced in 2012 involving all departments in defining the objectives, the targets, the related performance measures and the expected results. Some targets were fixed by the general manager in order to follow the regional guidelines leaving a little room to the involvement of the department managers in the budget negotiation process. Most of other targets were based on historical data ... they were the starting point of each negotiation between the controller and the department managers about the target definition! The objectives and the related targets were assigned to each department, identifying the performance measures which were mainly objective in order to avoid ambiguous interpretations".

Some arguments were developed about objectives and targets that were not drawn from the regional guidelines being defined upon past results in a budget negotiation. The objectives assigned to each department followed the hospital strategic vision described in the PP. In particular, objectives and targets were developed drawing on the measures of past results which constitute the "knowledge" about some performance dimensions.

The manager of Laboratory department underlined this aspect. He argued: "When I became the manager of this department, I immediately complained for the absence of objective performance measures used to evaluate my 
department. Before the merger between the two hospitals, my activities were evaluated through objective performance measures that made clear what performance dimension was to be evaluated... The performance dimensions and the related measures helped us in our task as they reflected the characteristics of the healthcare activities accomplished by the department... In the last year, during the budget negotiation, I proposed some examples of the objective performance measures used in the hospital B in order to underline how these measures could permit to focus the same target in the same way avoiding misunderstandings between administrative and professional people. Currently, the chemical laboratory was the only area whose performance were measured through objective parameters".

In this sense, the objective performance measures applied to chemical laboratory can be considered valid performance measures: they provided "the truth" for they reflected the characteristics of the department activities, helping physicians in their task. A logical, vertical coherence between the strategic objectives (theoretical level), the performance targets and measures (epistemic platform) and the characteristics of the department activities (phenomenological ground) is meaningful of a correspondence sense of truth. But, such a conception of truth is integrated with others. Physicians identified the same performance targets defined by the controller and the department manager during the budget negotiation. The manager of Laboratory department was able to know the truth having practised these performance measures in the hospital B. His previous experience helped the integration of measures of past results with measures estimating future outputs. Put it other way, the manager's previous experience helped integrate knowledge of clinical processes with professional beliefs. A proactive truth was in practice. The objective performance measures also reflected the professional values which motivated the physicians to act coherently with the department objectives. They better fit the characteristics of the department activities, supporting the communication among physicians and administrative staff. The new performance measures reflected the professional topoi related to the mode of thinking by which each physician of the Laboratory department perceives, interprets and understands the hospital activities. In this sense, the people involved in the planning process were supported by the manager of Laboratory department in investigating and understanding the world of this department in relation to its economic and institutional environment. A pragmatic concept of truth is at work.

Another important aspect of the planning process consists of making clear the characteristics of the performance measures. The financial accountant, who supported and cooperated with the controller during the budget negotiation, noted: "The objectives and the related performance measures must be clear, measurable and achievable! Coherently with the PP, the objectives assigned to each department were articulated in: strategic, operational and quality objectives. For each category, which represented an outcome dimension, we identified clear performance measures... for instance, the degree of hospitalisations of each department was measured by a fixed percentage of hospitalisations; the delivery of the inventories was measured by meeting the four deadlines set during the year. Any change in operating conditions might include a revision of the targets provided for the current year".

Moreover, there was a lack of objectivity in the performance measures adopted for some department. The financial accountant, in line with the manager of chemical laboratory department, highlighted the importance of clear, measurable and achievable performance measures. In his view, an important aspect was to define the performance concept underlying the performance measures in relation to the variables used in the measurement process at the operational level. For example, for the measure of hospitalisation the concept was recognised by the physicians who were confident with this kind of performance dimensions. Such a measure as the percentage of hospitalisations, representing an instrument of communication among administrative and professional people, met the hospital and the professional values aimed at increasing the number of patients admitted to the hospital. The meaning of the performance measures, in this case, was correctly understood. The logical, vertical coherence supports the communication coherence of the measures.

Differently, if people have an unclear understanding of the performance concept underlying a performance measure, they can interpret the same performance measure in different ways. Then, the measure may lack communicative coherence. For example, during the budget negotiation, the objective of reducing the average stay was assigned to the department of general medicine. The related performance measure, namely the length of stay, was defined by dividing the number of daily stays at a department by the number of patients admitted to that department. This objective and the related performance measure were redefined during the year because of the influence of some uncontrollable factor. Specifically, during the year, the department of general medicine has been forced to admit many patients coming from the emergency room. This fact made the "length of stay" performance measure uncontrollable. Used before this unpredicted fact, this performance measure reflected the value shared by its users and became part of the language used by the administrative and professional people. In order to preserve its validity, the performance measure was adjusted by re-establishing a correspondence between the measure and the fact that it represented. Thus, the adjustment required to divide the number of daily stays at a department by a proportion of the number of patients admitted to the hospital.

During the budget negotiation, the actors involved in the process were conscious that the performance measures adopted were required to provide reliable information. However, not always that happened. For example, the financial 
accountant highlighted what follows: "referring to the outcome measures provided in the PP, one was related to the patients wealth: the percentage of first therapeutic service provided by the department. This performance dimension was measured by the ratio between the number of services and the number of recoveries. The latter parameter was however improper for not all recoveries required a first therapeutic service!".

Thus, the performance measures have to be valid in order to be communicated to the relevant stakeholders. What has been discussed so far is a set of problems that have compromised to some extent the validity of performance measures in terms of factual correspondence and communicational coherence. The discussed problems were referred to performance measures that derived from process of negotiations among the hospital actors involved. Differently, referring to targets and objectives that the general manager fixed on the basis of the regional guidelines, in line with the implementation of the NPM principles, the validity of the performance measures depends on whether the external coherence can compromise the company coherence. In particular, referring to the outcome dimension related to the patient wealth, the PPs (20132016 and 2014-2017) contain two outcome measures: the number of the cardiovascular problems and the number of natural births. The healthcare services related to both performance measures were perceived as financially unfeasible, as their achievement required an increase in the cost level, damaging the hospital efficiency. Such performance measures were not built on factual possibilities for they did not consider the cost of providing these services. Moreover, they were not coherent with the national and regional guidelines of efficiency that the hospital has to follow in order to reduce the public cost related to healthcare services. Thus, the hospital values were not reflected by these measures, which showed a company incoherence. An institutional coherence was showed instead by the measures under discourse. In fact, these two performance measures were dictated by the national and regional constrains that obligated the healthcare organisations to maintain an acceptable level of the patient wealth. This example shows how the measures fixed and the related objectives and targets imposed by the national and the regional guidelines, that is centrally defined, did not reflect the resource constrains of the single hospital, and the company incoherence compromised the validity of those measures.

The last point is not a general argument as some adjustments could be possible. In order to increase the internal and external coherence of the performance measures, some adjustment was done during the year 2015. The measures related to the administering of drugs were revised in order to better evaluate their appropriateness considering the rules established for the regional reimbursement. Specifically, before its revision, this performance measure caught only the consumption of drugs in each department without being defined in relation to other concepts such as the hospital aggregate demand for drugs (lack of company coherence) and the regional constrains related to the maximum reimbursement admitted (lack of institutional coherence). Both the company and institutional coherences were pursued by the controller who, in evaluating the departments' requests for drugs, had to consider the constraints of the regional reimbursement. To this aim, he revised the department requests for drugs on the basis of the hospital aggregate demand for drugs

In the latest PP, related to the years 2014-2017, the controller highlighted some communication problem in certain performance measures that were centrally defined by the hospital top management. In particular, she argued that some performance objectives were not operationalised into measures. For example, regarding the disposal of real estate assets as a performance objective, the related measure was yes or no only. Thus, the degree of the achievement of this objective was not measurable. The critical aspects of this performance measure was: the absence of a defined threshold; the lack of involvement of administrative staff in defining the objective; the lack of knowledge of the process by those who formulated the objective and the related performance measures, ignoring the logical possibilities under the disposal of real estate asset. Considering all these points, the performance measure was not valid because the task of the PP for this performance dimension was not clear to the people who were involved in the planning process.

The lack of validity and consistency of the performance measures was also explained by the Manager of the radiology department: "Too often the general manager and the controller set vague and obvious targets. The reason can be found in our incentive system which is designed in order to avoid that different amount of bonus were distributed among medical managers. All medical managers had to be paid for their performance in order to satisfy a sense of fairness. No matter how relevant and difficult the result was. As a consequence, objectives were defined ambiguously so as to leave the medical managers with large room for justifying their failure. Moreover, the top management does not take into account the heterogeneity of activities. It encourages the increase in the volume services, but at the same time it requires a cost containment, without considering that most of the expenses are proportional to the volumes".

From the last quotation, a lack of validity involves the planning process as an organisational topos. It is the way the incentive system was thought about that lacks a value coherence. The value of fairness was perceived so important that any other value, such as hospital efficiency and effectiveness, was sacrificed. This was due to the great power that labour unions had acquired in the Italian economy, which influences all the healthcare system and single hospitals. This value incoherence can be declined into both institutional and company incoherencies. It explains why objectives were defined ambiguously and translated into measures that made the targets always reachable. 
The search for valid performance measures used in performance planning must not be limited to the measurement system, conceived of as a set of relations between performance concepts and measures (vertical dimension), and among the different performance concepts themselves (horizontal dimension). The search for valid performance measures as a system of learning has to go further, toward investigating the ways of thinking behind the system, their topoi, which are mostly organisational and institutional. These two topoi dimensions are so interrelated in any hospital performance planning that can be both summarised by the expression of "the performance measuring topoi of the hospital".

\section{$5 \quad$ Concluding remarks and research possibilities}

The present research aimed to discuss the theoretical conditions for validity in performance measures used in hospital planning. The originality of the present research stems from moving from the realistic paradigm and applying the pragmatic constructivism as a theoretical lens to point to the public hospital setting in order to address the above issue. Although we focus on performance measures, their validity has to be searched for behind the surface of the performance parameters: the validity of the performance measures contained in a PP has to be searched for in the performance measuring topoi of the hospital. This conclusion stems from two main results that can be drawn: firstly, from the general, theoretical discussion; secondly, from the empirical analysis referring to the healthcare setting.

The theoretical discussion, which refers to any kind of business, suggests examining the validity of performance measures, and to some extent of a PP, by verifying the extent to which the measures contained in the plan produce information on a truth that has to be viewed as a pragmatic truth: information that has to lead to successful actions. Such a pragmatic truth has to be pursued dynamically by following a learning approach to the search for validity and for truth. The four ontological dimensions (facts, possibilities, values and communication) come to be relevant for the design of a performance measurement system, whose validity is judged in terms of factual correspondence, logical coherence and consistency, value and communication coherence that are both internal to and external of the organisation. In order to base the evaluation of a set of performance measures on the criteria of correspondence, consistency and coherence just mentioned, the search for validity has to be oriented toward the performance measuring topoi, namely to the modes of thinking of the organisation in relation to performance measuring. The theoretical discussion constituted a useful lens to examine the empirical setting of the hospital under study.

The empirical analysis confirmed the reasoning followed in the theoretical part of the paper, adding specific results to the theoretical conclusion: the strict interdependence between the organisational and the institutional environment of any hospital suggests examining its performance measuring topoi considering both the organisational and the institutional as two dimensions that concurs simultaneously to shape the mode of thinking of an hospital in relation to performance measuring. A search for valid performance measures to be used in hospital planning requires a look to the hospital history which has to be investigated in terms of relations between the hospital organisation and its healthcare institutional environment. Thus, the distinction between company and institutional coherences does not seem to be so meaningful. Rather, the relations between organisational and institutional environments has to be emphasised.

Another point that emerged from the case evidence is how the planning process can affect the validity of the performance measures contained in it. As part of NPM reforms that have been introducing managerial tools in public organisations, performance measures can be introduced through a top-down process into a hospital. This is the case when the relevance of the objectives and targets to be measured is perceived at the national or the regional level. Thus, according to the relevance of the objective and targets that the hospital was planning to reach, the related measures could be defined drawing on the regional guidelines, fixed by the top management of the hospital or negotiated by the main hospital managers involved. What the case evidence has shown is that the risk of compromised validity is mostly higher in the cases of performance measures that were centrally defined.

Besides these points, another related to the specifics of healthcare setting is the co-presence of the two relevant logics that characterise any healthcare organisation, namely the managerial, administrative logic and the health professional one. These two logics and their organisational dynamics are examined in the accounting healthcare literature as reasons for resistance to failure or success of the accounting and administrative innovations that have pervaded the healthcare context (Weiner et al., 1987; Chua and Degeling, 1993; Covaleski et al., 1993; Doolin, 1999; Jacobs et al., 2004; Lehtonen, 2007; Conrad and Uslu, 2011; Kraus, 2012; Leotta and Ruggeri, 2012; 2017). From the point of view of pragmatic constructivism, the presence of these two logics and their organisational and institutional dynamics have to be considered as relevant antecedents of value and communication coherence that any process of performance planning has to pursue.

Adopting the pragmatic constructivism lens, this paper offers an empirical evidence of the theoretical framework in analysing the validity in performance measures in hospital PP. In particular, the co-presence of two main logics which characterised any hospital setting, was interpreted as multiple topoi that guided the organisational actors in recognising the validity of knowledge of past results, verifying the correspondence of performance measures with the 
past activity of the hospital. The main logics also played an important role in examining the validity of the estimations of future results by verifying their coherence and consistency. Pragmatic Constructivism shows to be a useful perspective to examine settings, such as hospitals, characterised by multiple rationalities. Interpreting the latter as multiple topoi Pragmatic Constructivism leads to an analysis of the conditions of their integration that are the same conditions for the validity of the performance measures in use.

The healthcare setting discloses to the young paradigm of Pragmatic Constructivism a wide range of possibilities for research. A line of research can address the question of how the search for valid performance measures can vary according to the institutional type of hospital: teaching vs. general; public vs. private and the like. Another line of research can investigate how the search for valid performance measures can vary considering different institutional environments. To this aim, an international comparative case study can be of interest. Alternatively, this second research line can be pursued through a longitudinal case study that develop a comparative discussion along the different historical periods of an healthcare organisation. A further line of research can address the issue of the convergence or divergence between the managerial and professional logics, considering them as two sub-organisational topoi. This line of research can examine how performance measures can support the convergence between the two sub-organisational topoi by means of measures that pursue value and communication coherence.

\section{References}

Abernethy, M.A. et al., 2007. Accounting and Control in Health Care: Behavioural, Organisational, Sociological and Critical Perspectives, in C.S. Chapman, A.G. Hopwood and M.D. Shields (eds.), Handbook of Management Accounting Research (Elsevier, Oxford).

Aidemark L.G. and E.K. Funck, 2009. Measurement and Health Care Management. Financial Accountability \& Management, 52(2): 253-76.

Chua,W. F., and Degeling, P. , 1993. Interrogating an accounting-based intervention on three axes: instrumental, moral and aesthetic. Accounting Organisations and Society, 18(4):291-318.

Conrad, L, and Uslu, P. G., 2011. Investigation of the impact of 'Payment by Results' on performance measurement and management in NHS Trusts. Management Accounting Research, 22, 46-55.

Covaleski, M. A., Dirsmith, M.W., and Michelman, J.E., 1993. An institutional theory perspective on the DRG framework, case-mix accounting systems and health-care organizations. Accounting Organisations and Society, 18(1):65-80.

Curtright, J.W. et al., 2000. Strategic Performance Management: Development of a Performance Measurement System at the Mayo Clinic. Journal of Healthcare Management, 45(1): 58-68.

Doolin, B., 1999. Casemix management in a New Zealand hospital: rationalisation and resistance. Financial Accounting Management, 14(3-4):397-417.

Jacobs, K., Marcon, G., and Witt, D., 2004. Cost and performance information for doctors: an internal comparison. Management Accounting Research, 15, 337-354.

Johanson, U. et al., 2006. Balancing Dilemmas of the Balanced Scorecard. Accounting, Auditing \& Accountability Journal, 19(6):842-57.

Kraus K., 2012. Heterogeneous accountingisation. Accounting and inter-organisational cooperation in home care services. Accounting, Auditing \& Accountability Journal, 25(7): 1080-1112.

Lehtonen, T., 2007. DRG-based prospective pricing and case-mix accounting - Exploring the mechanisms of successful implementation. Management Accounting Research, 18, 367-395.

Leotta, A., Ruggeri, D., 2012. Changes in performance measurement and evaluation systems as institutional processes: the case of an Italian teaching hospital. In Performance Measurement and Management Control: Global Issues - studies in managerial and financial accounting, 25, edited by Antonio Davila, Marc J. Epstain and Jean-Francois Manzoni, Emerald Group Publishing Ltd.

Leotta A., Ruggeri D., 2017. Performance measurement system innovations in hospitals as translation processes. Accounting, Auditing \& Accountability Journal, 30 (4):955-978.

Moullin, M., 2004. Evaluating a Health Service Taskforce. International Journal of Health Care Quality Assurance, 17(5): 248-57.

Norreklit, H., 2003. The Balanced Scorecard: What is the Score? A Rhetorical Analysis of the Balanced Scorecard. Accounting Organisations and Society, 28(6): 591-619.

Nørreklit, H., 2014. Quality in qualitative management accounting research. Qualitative Research in Accounting \& Management, 11 (1):29-39.

Nørreklit, H., Nørreklit, L., Mitchell, F., 2007. "Theoretical conditions for validity in accounting performance measurement", in Neely, A. (Ed.) Business Performance Measurement - Frameworks and Methodologies, Cambridge University Press, Cambridge, 179-217. 
Nørreklit, H., Nørreklit, L., Mitchell, F., 2010. Towards a paradigmatic foundation for accounting practice. Accounting, Auditing \& Accountability Journal, 23 (6): 733-758.

Nørreklit, L., Nørreklit, H., Israelsen, P., 2006. Validity of management control topoi - towards a constructivist pragmatism. Management Accounting Research, 17 (1): 42-71.

Northcott, D. and N. France, 2005. The Balanced Scorecard in New Zealand Health Sector Performance Management: Dissemination to Diffusion. Australian Accounting Review, 15( 3): 34-46.

Radnor, Z. and B. Lovell, 2003. Success Factors for Implementation of the Balanced Scorecard in a NHS Multi-Agency Setting. International Journal of Health Care Quality Assurance, 16( 2): 99-108.

Voelker, K.E., J.S. Rakich and G.R. French, 2001. The Balanced Scorecard in Healthcare Organizations: Performance Measurement and Strategic Planning Methodology. Hospital Topics, 79 (3): 13-24.

Weiner, S. L., Maxwell, J.H., Sapolsky, H.M., Dunn, D.L., and Hsiao, W.C., 1987. Economic incentives and organisational realities: managing hospitals under DRGs. Milbank Quarterly, 65(4): 463-487.

Zelman, W.N., G.H. Pink and C.B. Matthias, 2003. Use of the Balanced Scorecard in Health Care. Journal of Healthcare Finance, 29( 4): 1-16. 